\title{
EL JUICIO POR JURADOS POPULARES: LA EXPERIENCIA EN LA PROVINCIA DEL NEUQUÉN
}

Florencia Martini $^{83}$

RESUMEN: El ensayo analiza el Derecho Penal en su faz ejecutiva y los derechos de los sujetos que habitan en las fronteras socioculturales internas a los Estados, encubiertas por la "norma" estatal que sintetiza la mirada y disciplina. Devela el funcionamiento de nuevos dispositivos de participación ciudadana que horadan la unidad impuesta por la norma, abriendo la trama y permitiendo en ese proceso, el ejercicio real y efectivo de los derechos de ciudadanos culturalmente diversos (implicando el derecho a la diferencia, la discriminación positiva y su proyección en la toma de decisiones de la res pública como cosa de todos). Se trata del Jurado Popular, instituido en la Provincia del Neuquén que asigna competencia a los ciudadanos para el juzgamiento de conciudadanos acusados de cometer delitos graves contra las personas y la integridad sexual. Doce ciudadanos de distinta extracción sociocultural, con equitativa proporción de hombres y mujeres, que deliberan, argumentan y deciden en condición de simetría recíproca. Sumado ello el instituto faculta la integración del jurado con integrantes de los pueblos originarios cuando el hecho a juzgar comprometa el modo de resolución de conflictos de la comunidad, garantizando la diversidad cultural. Se tiende, de este modo, a la democratización profunda de la justicia y a proveer a su legitimación política y social, aspirando a la toma de decisiones más justas, con el compromiso de los conciudadanos de asumirse como participantes en el proceso del juzgar a sus pares.

Palabras claves: Interculturalidad; Jurado Popular.

RESUMO: O trabalho analisa a legislação penal em seu rosto executivo e os direitos das pessoas que vivem nas fronteiras sócio-culturais internas aos Estados, escondido pelo estado "padrão" que sintetiza o olhar e disciplina. Revela novos dispositivos que executam a participação do

\footnotetext{
${ }^{83}$ Abogada, especialista en derecho penal y ciencias penales. Doctora en Derecho. Miembro del proyecto de investigación "Globalización y Contrahegemonia" de la Facultad de Lenguas de la Universidad Nacional de Córdoba, Argentina y Jueza del Tribunal de Impugnación de la Provincia de Neuquén, Argentina (Poder Judicial de Neuquén).
} 
cidadão perfure a unidade imposta pela norma, a abertura do terreno e no processo de permitir o exercício real e efectiva dos direitos de culturalmente diversos cidadãos (envolvendo o direito à diferença, a discriminação positiva e sua projeção na tomada de decisão de res públicos). Esta é a Júri Popular, estabelecida na província de Neuquen, que atribui competência para julgar cidadãos para os cidadãos acusados de cometer crimes graves contra a pessoa e integridade sexual. Doze cidadãos, desde a extracção cultural diferente, com igual proporção de homens e mulheres, que deliberam, discutem e decidem na condição de simetria recíproca. Além disso, ele permite que o instituto júri integração com os membros dos povos indígenas ao julgar o fato de cometer modo comunidade resolução de conflitos, garantir a diversidade cultural. Ele tende, assim, para a democratização profunda da justiça e buscar a sua legitimidade política e social, com o objetivo de tomar decisões mais corretas, com o compromisso dos cidadãos para assumir como participantes no processo de julgar os seus pares.

Palavras-chave: Interculturalidade; Jurado Popular.

\section{Introducción}

Cuando referimos al Jurado Popular, no lo hacemos en la acepción corriente de justicia popular, como mecanismo informal de acción directa, también llamada "justicia por mano propia" que se identifica con los linchamientos populares realizados por un conjunto de individuos que espontáneamente reaccionan ante un hecho administrando justicia por sí mismos ante la presunta omisión del sistema estatal. El jurado popular es una institución social que forma parte de la administración del castigo estatal e implica la intervención de ciudadanos de la comunidad en la que se cometió un delito, en el juzgamiento de sus pares por la infracción de la ley penal que se promulgó en su nombre y en su beneficio encaminada a la convivencia pacífica de los miembros de la comunidad.

El jurado popular se encuentra regulado por la ley en dos sentidos (en atención al sistema federal del Estado Argentino):

a) Ley de procedimiento del Estado provincial en el que se juzga al "conciudadano" acusado de infringir la ley (como infracción al contrato social) e indica el modo en que se convoca a los potenciales jurados, el modo en que se seleccionan los miembros que han de integrarlo y las 
El juicio por jurados populares: la experiencia en la provincia del Neuquén | 243

reglas que han de seguir tanto durante el juicio como después de éste al momento de deliberar y emitir un veredicto y,

b) Ley penal del Estado Nacional que establece qué acciones constituyen delitos, qué permisos o justificaciones eximen al autor de aquellas y cuándo puede reprochársele al sujeto infractor la conducta cometida. La ley aplicable al caso concreto se explica al jurado popular a través de las denominadas "instrucciones" que son dadas por quien dirige el juicio, el juez técnico, a propuesta de las partes, el defensor del acusado, el fiscal (acusador púbico que representa a la sociedad afectada por el delito) y en ocasiones, por el querellante particular, que representa a la víctima del delito (acusador particular).

La participación ciudadana que implica el juzgamiento de delitos por jurados populares reúne a los individuos y su voluntad particular con la ciudadanía y la voluntad general, acercando los extremos de ámbitos que han sido disociados a través de la burocracia estatal. Constituye una forma de materializar la democracia y revivificar la república; promover el entendimiento público de la ley y del procedimiento legal, proporcionando legitimidad al sistema penal, y a la institución social del castigo.

La penalidad o castigo, entendido en términos de control social pero también como ratificación de los valores y creencias compartidas por la comunidad que refuerzan la norma penal como así ejercicio legal de la "violencia" estatal a través de la privación de libertad de los conciudadanos que quebrantan el pacto social. En este último sentido debe ser ejercido como "última ratio" (última instancia ante el fracaso de otros dispositivos no penales para la pacificación social).

Debido a que los sistemas de toma de decisión con jurados extraen a la gente de múltiples subgrupos de la comunidad, un grupo de jurados o jueces legos es más probable que representen muchísimo mejor que los jueces de élite la gama de puntos de vista y las actitudes de la comunidad en general. Esta representatividad contribuye directamente a la determinación de los hechos porque las experiencias de vida, los puntos de vista y las actitudes configuran cómo la gente evalúa el conflicto penal. El hecho de que los determinadores legos de los hechos tengan más probabilidades de reflejar las características sociales y políticas de la comunidad ayuda a asegurar que los fallos judiciales estén en línea con las actitudes comunitarias. (HANS, 2014, p.83-84) ${ }^{84}$

${ }^{84}$ La participación plena entre jurados de diversos entornos le permite al jurado basarse fuertemente en experiencias personales, perspectivas sociales y conocimientos que difieren 
Los teóricos han afirmado que la participación en el juzgamiento promueve la democracia participativa, se ha dicho que educa al pueblo sobre la ley como así también impulsa otras formas de participación política (LEVINE, 1992; LEMPERT, 2002). Ciudadanos comunes que deciden en jurados alcanzan sus decisiones luego de una deliberación. Como estos grupos incluyen a individuos que provienen de diferentes entornos y experiencias, la deliberación del caso es más probable que sea rica. Aunque los ciudadanos comunes también pueden ser sujetos a las influencias del a corrupción, existen menos posibilidades de corrupción sistemática, porque el jurado decide solo un caso.

El jurado constituye un cuerpo ideal para inyectar el sentimiento de la comunidad en un juicio. Las comunidades son heterogéneas, diferenciándose a través de muchas dimensiones como el género, la raza, la etnia, la religión y los ingresos económicos. Si el sistema de selección tiene éxito en extraer como jurados a individuos de cada uno de estos múltiples subgrupos en una comunidad, la deliberación permite el intercambio de diversos puntos de vista sobre el caso. De esta manera, las ideas de la comunidad sobre lo que es justo y equitativo en un caso son inyectadas en el proceso de toma de decisión el jurado y del juez lego. Investigaciones teóricas y empíricas sobre el modelo narrativo que emplean los jurados para la toma de sus decisiones sugiere que los jurados desarrollan un relato narrativo, o una historia de lo que sucedió en el caso. El jurado procesa la prueba presentada durante el juicio, organizándola en una historia coherente acerca de lo que sucedió. Los jurados se basan en su propio conocimiento del mundo, sus experiencias previas, sus preconceptos y sus creencias para construir esa historia proporcionando un vehículo que permite que los estándares y expectativas de la comunidad sean incorporados en los veredictos. Los jurados incorporan a la ley su enfoque del sentido común de justicia que, a veces, puede divergir del enfoque judicial. (HANS, 2014, p.34-35)

La participación de los miembros de la comunidad afectada por el delito en el juzgamiento de sus pares permite el ejercicio responsable de la ciudadanía a través de la asunción del conflicto que los implica como

entre individuos y grupos sociales. Jurados de diversos entornos pueden involucrarse en deliberaciones de amplio espectro que incluyen tópicos y consideraciones que podrian perderse o incluso ser evitadas, cuando exista menor diversidad entre sus miembros. Por lo tanto, cuando los miembros del jurado provenientes de diferentes segmentos de la comunidad participan activamente en la deliberación, es más probable que mayor información relevante sea presentada e intercambiada. Como resultado, los veredictos deberian ser reflejos mucho más precisos del conocimiento y las perspectivas comunitarias. 
El juicio por jurados populares: la experiencia en la provincia del Neuquén | 245 miembros de la comunidad en la que se manifiesta la infracción a la norma penal. Implica dentro de los límites impuestos por las normas regulatorias, que los ciudadanos se hagan cargo de este "otro" a quien se le imputa haber lesionado bienes sociales (integridad física, integridad sexual, etc), a efectos de fijar su responsabilidad frente a la sociedad a partir de los principios que constituyen el debido proceso legal. En este contexto, coloca a los ciudadanos en un cuerpo a cuerpo -desde sus propias miradas y creencias como así experiencia personal, con ese otro que forma parte del mismo entramado social y cultural al que ellos pertenecen aun reconociendo la singularidad de aquel.

En tal sentido se produce una doble transformación: en primer lugar de individuos pasivos, demandantes frente a la Administración de Justicia, a sujetos sociales y actores políticos con capacidad de intervención efectiva en la resolución de conflictos que los comprometen. Y, en segundo lugar, al nivel de la percepción del otro, desde la deconstrucción del "enemigo" (como fuente permanente de acciones potencialmente lesivas) a la de un conciudadano que ha quebrado el pacto social (a través de una conducta concreta desplegada en cierto contexto).

Paralelamente se promueve otro cambio de significación en la relación de los individuos con el poder encargado de la administración de justicia penal, que apunta a un acercamiento, en un sentido republicano, de los individuos al cuerpo político como identidad de objetivos y voluntades. Ambos procesos de cambio se encaminan a superar las antinomias del buen vecino y buen ciudadano respecto del delincuente y del sistema penal estatal respecto de la sociedad.

\section{Regulación legal del Juicio por Jurados}

El código de procedimiento penal de la Provincia del Neuquén establece una doble competencia para el juzgamiento de delitos cometidos en la provincia, a saber la de los jueces técnicos y la del jurado popular. Este último queda reservado para juzgar delitos contra las personas, la integridad sexual o cualquier otro delito cuyo resultado haya sido muerte o lesiones gravísimas, siempre que el Ministerio fiscal solicite una pena privativa de libertad superior a quince años.

El tribunal de Jurados se integrará con doce jurados titulares y cuatro suplentes. La dirección del juicio estará a cargo de un juez profesional. Para ser jurado popular se requiere ser argentino, tener veintiún años de edad, estar en pleno ejercicio de los derechos 
ciudadanos, tener domicilio conocido, con una residencia permanente no inferior a dos años en el territorio de la jurisdicción del tribunal competente y tener profesión, ocupación, oficio, arte o industria conocida.

Se encuentran impedidos de integrar el jurado los abogados, los mayores de setenta y cinco años de edad, el gobernador y vicegobernador de la provincia y sus ministros, los titulares del Poder Ejecutivo comunal, los funcionarios auxiliares del Poder Judicial, Ministerio Público y Defensa Pública, los miembros en servicio activo de las Fuerzas Armadas o de Seguridad y de la Policía Federal y Provincial, los ministros de un culto religioso, los que tengan sentencia condenatoria ejecutoriada a pena privativa de libertad por delito doloso o los que estén formalmente sometidos a proceso penal.

A efectos de garantizar la conformación de los tribunales de jurados, el primer mes de cada año judicial se realizará una lista inicial de jurados elaborada por la Justicia Electoral de la provincia del padrón electoral por sorteo y en audiencia pública, separados por circunscripción y por sexo y a remitirá al Poder Judicial el primer dia hábil del mes de noviembre con publicación en el Boletín Oficial, en este sorteo participan como veedores un representante del Colegio de Abogados de cada circunscripción, representantes de la Asociación de Magistrados y a las demás entidades vinculadas con el quehacer jurídico.

Cualquier ciudadano está facultado a observar los listados, dentro de los quince días de publicados, cuando existan errores materiales o incumplimiento de alguno de los requisitos legales. La función de jurado es una carga pública obligatoria y será remunerada en caso de empleados por el empleador y en caso de independientes o desempleados, con la suma de medio JUS diario. Dentro de los diez días hábiles judiciales previos al inicio del juicio la Oficina Judicial sorteará en presencia obligatoria de las partes (fiscal y defensor) una lista no menor al doble de jurados requeridos (32) y se los convocará a una audiencia de selección de jurados y en la misma oportunidad se sorteará e juez profesional que tendrá a cargo la dirección del juicio. La audiencia de selección del jurado tiene por fin constituir el jurado imparcial para resolver el caso. Quienes tengan motivo para excusarse podrán hacerlo y luego se procede a las recusaciones por las partes, previo examen y contraexamen sobre posibles circunstancias que pudieran afectar su imparcialidad. También pueden las partes recusar sin causa a uno de los jurados titulares. Concluido el examen serán designados formalmente advirtiéndoles la importancia y deberes de su cargo. 
El juicio por jurados populares: la experiencia en la provincia del Neuquén | 247

La integración del jurado debe ser plural. Deberá quedar integrado por hombres y mujeres en partes iguales tratando de que, como mínimo, la mitad del jurado pertenezca al mismo entorno social y cultural del imputado. Se tratará también, en lo posible, que en el panel de jurados haya personas mayores, adultas y jóvenes.

El hecho de prever una integración igual de hombres y mujeres se presenta como una exigencia de igualdad en la participación y de igualdad de estatus social. Puede leerse esta previsión de integración igualitaria de géneros como una política pública que estatuye cupos, para garantizar la participación de mujeres en el espacio público, en un ámbito que tradicionalmente estuvo reservada a los hombres como lo es la administración de la penalidad. De este modo repara una desigualdad fáctica entre los ciudadanos asegurando la efectiva participación como iguales en la interacción social.

El juicio se realiza en dos fases. En la primera se trata todo lo relativo a la existencia del hecho y la responsabilidad penal del acusado. Finalizada esa etapa el jurado deberá determinar si se han probado los hechos materia de acusación y si la persona juzgada es culpable o inocente. Cuando haya un veredicto de culpabilidad, en la segunda etapa, con interviene exclusivamente un juez profesional que determina la pena de conformidad de conformidad a la escala penal del delito por el que fuese declarado culpable el acusado. Es entonces con el veredicto de culpabilidad o no culpabilidad que finaliza la actuación del jurado popular.

Los alcances de la participación del jurado popular se advierten desde el inicio de la audiencia cuando prestan juramento solemne ante el juez. Los jurados se ponen de pie y el oficial de sala pronuncia la siguiente frase: "juráis en vuestra calidad de jurados en nombre del Pueblo, a examinar y juzgar con imparcialidad y máxima atención la causa, dando en su caso el veredicto según vuestro leal saber y entender, observando la Constitución de la Nación, de la Provincia del Neuquén y las leyes vigentes? Realizado el juramento se declara abierto el juicio, se advierte al imputado sobre la importancia y el significado de lo que va a suceder y se cede la palabra al fiscal y al querellante para que expliquen el hecho del juicio, las pruebas que se producirán para fundar la acusación y la calificación legal. Luego se invita al defensor a que explique las líneas de su defensa. En el curso de la audiencia el imputado puede hacer las declaraciones que considere oportunas y las partes formularle preguntas o requerirle aclaraciones. 
Una vez producida la prueba (oídos los testimonios) se declara clausurado el debate y el juez invita a los jurados a retirarse de la sala y se celebra una audiencia con los abogados de las partes a fin de que propongan instrucciones a impartir a los jurados. Finalizada la audiencia de instrucciones el juez hace ingresar al jurado a la sala de juicio. Primero le explica las normas que rigen la deliberación, entregándoles copia de ellas por escrito y les informa el deber de pronunciar el veredicto en sesión secreta y continua. Luego les imparte las instrucciones. Les explica los puntos controvertidos del caso, las cuestiones esenciales a decidir y las disposiciones legales aplicables al caso, expresando su significado y alcance en forma sencilla y clara. Inmediatamente después los jurados pasan a deliberar en sesión secreta y continua en la que únicamente deben estar la totalidad e sus miembros titulares. Los jurados elegirán su presidente, bajo cuya dirección analizaran los hechos. La votación será secreta.

Las instrucciones defectuosas pueden dar lugar a una incorrecta resolución del caso, por lo que las partes pueden hacer protesta de las instrucciones propuestas y rechazadas por el juez técnico a fin de facultar una eventual impugnación contra la sentencia definitiva si fuese adversa al acusado. El veredicto deberá versar sobre cada hecho y cada acusado en torno a dos cuestiones: si está probado o no el hecho en que se sustenta la acusación y si es culpable o no el acusado. El veredicto de culpabilidad requiere como mínimo de ocho votos, de lo contario el veredicto será de no culpabilidad.

A diferencia de las sentencias de responsabilidad de los jueces profesionales, en las cuales quedan por escrito los argumentos que fueron tenidos en consideración para arribar a la decisión, la sentencia de responsabilidad -escrita por el juez técnico- sólo transcribe las instrucciones y el veredicto. Esto no significa, sin embargo que la decisión sea inmotivada, sino que la misma consiste en las instrucciones seguidas del veredicto que las constata afirmativamente en caso de culpabilidad o bien las deshecha en caso de no culpabilidad. Si se demostrase que el veredicto es contrario a la prueba producida en el juicio, el acusado tiene la facultad de impugnarlo por este motivo ante un tribunal de jueces profesionales, dando las razones del caso, y señalando la contradicción entre la prueba concreta y la decisión adoptada. Los jueces profesionales tienen acceso al video filmación del juicio para contrastar los extremos señalados por el impugnante y anular la decisión cuando se constatase manifiestamente que el veredicto ha sido contrario a la prueba producida. 
El juicio por jurados populares: la experiencia en la provincia del Neuquén | 249

Los miembros del jurado tienen la obligación de denunciar ante el juez por escrito, a través del presidente, sobre cualquier tipo de presiones, influencias o inducciones externas que hubiesen recibido para emitir su voto en un sentido determinado. Asimismo están obligados a mantener en absoluta reserva su opinión y la forma en que han votado. Las boletas utilizadas para la votación para la votación serán destruidas de inmediato una vez obtenido el veredicto, cuidando de que no tomen conocimiento de ellas personas ajenas al jurado.

Cuando se haya logrado el veredicto, el jurado será convocado de inmediato a la sala de la audiencia, a fin de que su presidente dé lectura a lo resuelto. De acuerdo al veredicto, se declarará, en nombre del Pueblo, culpable o no culpable. Con este pronunciamiento finalizará la intervención de los jurados.

\section{La penalidad en las fronteras}

El castigo es una institución social compleja que refleja no sólo la idea instrumental del control social sino también la moralidad social asentada en los valores de una comunidad que se ven alterados por la infracción del autor del delito, lo que conlleva -tal como lo sostiene Durkheim- al refuerzo de la solidaridad social. El castigo debe ser considerado como expresión de valores, sensibilidad y moralidad social más que como un medio para lograr un fin penitenciario (exclusión del "delincuente", resocialización, prevención general -como amenaza a la comunidad a fin de reforzar la norma-, lisa y llana retribución, etc.). En este sentido, la administración del castigo manifiesta las fronteras internas de un Estado compuesto por sectores diversos e individuos distintos ${ }^{85}$ atravesados por la moral hegemónica que impone la norma estatal.

${ }^{85} \mathrm{Tal}$ como lo propone Emmanuel Levinas (Totalidad e Infinito. Ensayo sobre la exterioridad, Salamanca, Ed. Sigueme, 1977) y lo sostiene luego Enrique Dussel (Filosofia Etica Latinoamericana I, Presupuestos de una Filosofía de la Liberación, México, Edicol, 1977, p.120) lo dis-tinto indica la diversidad y no supone unidad previa: es lo separado, no necesariamente procedente de la identidad originaria. La diferencia supone la unidad: lo Mismo, procedente de la identidad que como Totalidad los comprende. La alteridad en la historia de la metafisica occidental fue entendida como un despliegue interno que es solamente una escisión de sí, un ponerse a sí mismo como otro. Ser otro es un momento del movimiento dialéctico: "la negación, no ya como la nada abstracta, sino como un ser determinado, es un algo; es el ser como otro". Lo Mismo, designa una ontologia de la identidad o "dialéctica monológica" que se constituye por un movimiento entre dos instancias: la identidad y la di-ferencia. A ella opondrá la dis-tinción cuya noción principal es la analogia. Se trata de una analéctica dialógica. Lo diferente es lo arrastrado desde la identidad, in-diferencia originaria o unidad hasta la dualidad. 
"Que un Estado le aplique un castigo a algunos de sus ciudadanos tiene el carácter de una guerra civil en miniatura: muestra a una sociedad enfrascada en una lucha interna. Y si bien en ocasiones esto puede resultar necesario, nunca será más que un mal necesario. El castigo es una expresión moral y no algo meramente instrumental" (GARLAND, 1999, p. 338). sentido:

La penalidad actualiza el concepto de frontera en un doble

Las fronteras se manifiestan entre los diversos otros dentro del nosotros de una comunidad concreta. Diversos Otros estatuidos a partir de diferencias de clase, género, origen étnico, etc. como identidades disimiles que constituyen una supra identidad, de algún modo impuesta por razones históricas, sociopolíticas y económicas que nos trascienden como lo es el Estado Nacional representado por la "Norma Fundamental" que encarna la Constitución Estatal. Estos diversos Otros ingresan a la estructura del sistema de la penalidad, al integrar el Jurado Popular como institución destinada a juzgar a quien se encuentra acusado de cometer un delito y por tanto, acusado de haber lesionado bienes primarios de la comunidad de la que forman parte estos Otros.

Asimismo se manifiesta en la fronteras del Uno (el buen ciudadano, el buen vecino) versus el Otro ("delincuente") esta dicotomía nos interpela: ¿qué estamos haciendo mal como sociedad? o ¿qué sistemas informales están fallando en el control del delito en la comunidad donde se manifiesta la infracción a la ley penal como representación de la infracción al pacto social?, y visto desde otra perspectiva, ¿en qué medida necesitamos de esos Otros para reafirmar la pertenencia del Uno al Nosotros? Esta frontera está dada por la exclusión del Otro, como individuo des-sujetado por el Estado en instancias previas a la comisión del delito (BUTLER, 2009, p. 66) y por la consecuente exclusión del Otro por parte de los conciudadanos y miembros de la comunidad a partir de la estigmatización del otro como delincuente una vez que es declarado culpable por los operadores del sistema penal.

\section{La experiencia de participar como miembros del Jurado Popular en la Provincia del Neuquén}

De las encuestas realizadas a los integrantes de a los Jurados Populares en la primera circunscripción de la Provincia del Neuquén se recogen la siguiente información: De 267 integrantes correspondiente a diecisiete Juicios por Jurados (204 titulares y 65 suplentes), realizados 
El juicio por jurados populares: la experiencia en la provincia del Neuquén | 251

desde la entrada en vigencia de la nueva ley procesal (14/01/14) al $15 / 09 / 15$, en relación a la edad de los participantes, el $27,14 \%$ corresponde a personas de 31 a 40 años, el 26, $77 \%$ de 18 a 30 años, el $21,19 \%$ de 41 a 50 años, el $16,36 \%$ de 51 a 60 años, el 7,43 \% de 61 a 70 mientras que el $1,12 \%$ más de 70 años.

En relación al lugar de residencia el $69,14 \%$ corresponden a la ciudad de Neuquén mientras que el 30,1\% restante se corresponden a distintas localidades adyacentes a la ciudad de Neuquén.

Respecto al nivel de estudios, el $24,91 \%$ posee estudios secundarios incompletos, el $20,45 \%$ posee estudios secundarios completos, el $14,50 \%$ posee estudios universitarios incompletos, el $11,90 \%$ posee estudios primarios completos, el 8,92 posee estudios universitarios completos, el 7,06\% posee estudios terciarios completos, $6,69 \%$ posee estudios terciarios incompletos, el $4,46 \%$ posee estudios primarios incompletos, mientras que el $0,74 \%$ no posee estudios.

Por actividad laboral los porcentajes se distribuyen: 31,23\% relación de dependencia de carácter privado, 18,59\% relación de dependencia de carácter público, 11,90\% autónomos, 9,29\% ama de casa, desocupados $7,81 \%$ y jubilados $5,20 \%$.

El $77,70 \%$ de los participantes no han sido víctima de algún delito, el $63,20 \%$ no poseía conocimientos de procedimiento penal, el $40,52 \%$ poseía una opinión regular de la justicia penal mientras que el 39, 41\% una opinión buena, sólo el 8,18\% muy buena y el 5,58\% mala.

En relación a la reacción al recibir la notificación para participar como integrante, al 40,15\% le generó inquietud, al 30,48\% aceptación, al $13,75 \%$ aceptación y al 10,04 rechazo.

El 75, 46\% no pensó en excusarse de ser miembros del Jurado. Ante la audiencia de selección de integrantes del Jurado el 51,30\% se sintió bien, el $31,97 \%$ muy bien, el $12,64 \%$ regular mientras que el $2,97 \%$ mal. Para el $76,58 \%$ la información recibida en esa audiencia fue suficiente.

El 91,70\% no tuvo dificultad en el desarrollo de las audiencias del debate, el $74,72 \%$ no tuvo dificultades para comprender las exposiciones de las partes, testigos y peritos.

Durante la deliberación del Jurado (realizada por 204 miembros titulares), el 89,22\% pudo exponer sus conclusiones y el 79,41\% sintió que contribuyó con su aporte a la solución del caso. El 90,69\% no tuvo dificultad durante la deliberación y hasta la emisión del voto en el cumplimiento de su rol como integrante del Jurado. Al 54,72\% le resultó 
una experiencia muy positiva, al $36,60 \%$ positiva, al $3,77 \%$ regular mientras que sólo al 1,89\% muy mala.

El 50,19\% no cambiaría nada mientras que el 17,36\% modificaría los tiempos solicitados para la función. El 66,04\% considera que el sistema de Juicio por Jurados Populares ofrece suficientes garantías a las partes.

\section{La teoría de la acción comunicativa aplicada a los jurados}

El procedimiento de sorteo y selección de los miembros del jurado como así las instrucciones que aquellos reciben para deliberar y resolver en consecuencia, fija la pauta de la igualdad recíproca de los ciudadanos que lo integran así como su neutralidad frente a las partes del conflicto (acusado y víctima) lo que se denomina Imparcialidad. Exige un ejercicio de superación del interés privado del individuo y de su voluntad particular, afirmando una voluntad general que debe resultar de la deliberación racional que abreva del suelo de creencias y valores de los miembros de la comunidad afectada.

El suelo de la decisión que adopta el jurado es la deliberación entre pares e iguales, en condiciones simétricas encaminadas a la obtención de un consenso que legitima la aplicación de la ley al caso, fundando una nueva ley sancionada por un cuerpo deliberativo de doce personas de diferentes estratos sociales.

La teoría de la acción comunicativa sostenida por Habermas resulta un medio destinado a acercar los reclamos del comunitarismo y a no perder de vista que la razón práctica necesita del contexto del bien definido en sociedades históricas y así el kantismo reducido a la moral que Habermas denuncia en Rawls, es conciliado con el Hegel defensor de la ética ${ }^{86}$.

El universalismo de los principios jurídicos se refleja en un consenso procedimental que ciertamente ha de verse inmerso, al modo de un patriotismo constitucional, en una cultura politica históricamente situada que abreva de las normas comunitarias de equidad, de las normas de la tierra.

El jurado aprecia la prueba desde su íntima convicción y el sentido común de la comunidad a la que pertenece (ley común del lugar). Sin embargo la praxis deliberativa del jurado está sometida a la ley escrita y a

\footnotetext{
${ }^{86}$ La teoria habermasiana vislumbra la tensión entre la moral universal de Kant y la ética conectada a cada sociedad particular de Hegel.
} 
El juicio por jurados populares: la experiencia en la provincia del Neuquén | 253

los principios del derecho, que ingresa al debate a partir de las instrucciones recibidas por parte del juez técnico, al modo del legislador roussuniano, por lo que su racionalidad remite a la legitimidad del derecho válido. Ésta a su vez depende de la racionalidad de un proceso legislativo que, bajo las condiciones de la división jurídico-estatal de poderes, no queda librada a la disposición caprichosa de los miembros del jurado.

Tal como nos lo recuerda Carlos González Peña (1997, p. 43-50), resulta decisivo el giro operado por Habermas en su libro Facticidad y Validez, donde viene a reconocer la importancia del Derecho como vía que asegure las condiciones de un posible diálogo racional. Pero el carácter procedimental y formal no basta para legitimar el Derecho positivo. Un estudio del constitucionalismo y su evolución, con un análisis del denominado "derecho de gentes", es el que conduce a Habermas a ver en el Derecho la vía procedimental para asegurar una razón legitimadora de los derechos del hombre, en la que se forman nexos de integración entre voluntades particulares que abrevan de las normas comunes de equidad comunitaria, que legitiman al mismo tiempo que son modelados por la realidad legal del derecho, que se mueve siempre entre la facticidad y la validez.

Ni la ley por si sola; ni el legislador por sí solo; ni la voluntad por sí sola: el juego de una interacción continua entre legislación emanada de una autoridad, junto a una voluntad politica que se expresa por los canales de una sociedad legislada y legalizada como manifestación de agentes racionales y libres que se mueven por un sentido universalizable de la justicia, da lugar a la concepción moderna del derecho en el ámbito de las sociedades desacralizadas o laicas.

Habermas se aproxima a Rawls en su idea de que la razón, en su uso práctico y político, como indicara Rousseau, necesita del concurso colectivo, al mismo tiempo que paradójicamente es autónoma. En este intento de ligar a Rousseau con Kant se mueve todo pensamiento, que no puede dejar de ser paradójico, que se enfrente con la cuestión que confronta a la racionalidad de la ley con la libertad y a ambas, con la cuestión de la justicia.

La "posición originaria" de Rawls o la "comunidad ideal de diálogo" de Habermas, no son nada más que la representación de un ideal de justicia que busca trasladar el sentido interno de justicia, que apela a la autonomía moral y supone la capacidad del libre uso de la razón en el trato igual y equitativo entre todos los agentes morales, racionales y 
libres en el marco de la cooperación necesaria para la construcción de la polis humana, y el perfeccionamiento cívico/moral.

Tanto Rawls como Habermas favorecen, como es evidente, una vinculación entre ética y democracia, y sus teorías pueden ser examinadas como poderosas argumentaciones en favor de las instituciones democráticas. Rawls justifica las instituciones democráticas porque sus principios equivaldrían, de una manera relevante, a aquellos que personas racionales acordarían para cooperar entre sí en condiciones de imparcialidad. Habermas, por su parte, sugiere que las instituciones jurídicas de la democracia favorecen el debate moral en condiciones cercanas a aquellas que define idealmente la ética discursiva.

En sintonía con su teoría de sociedad en dos niveles -sistema y mundo de la vida- su teoría normativa va a necesitar de un complemento fáctico, que, residente en el poder político, es menester poder incluir dentro de un modelo de democracia que recoja la vieja inquietud de moralización de la práctica política.

Habermas sostiene la distinción de moralidad y eticidad, y pretende sumar a la dimensión privada de la autonomía, la dimensión pública: la capacidad de participar activamente en la formación de la voluntad política efectiva, que permita un acceso a la esfera pública de todos aquellos grupos que se consideran marginados, oprimidos o lesionados en su respeto y dignidad. Realiza una relectura de su tesis de la colonización del mundo de la vida en el nuevo escenario de la globalización, proponiendo un modelo federativo que renueve la ética cosmopolita kantiana en un sentido multiculturalista, "post-nacional", que revitalice de este modo la capacidad de decisión y de control por parte de una política moralizada -su modelo de democracia deliberativasobre la propia dinámica globalizadora de los sistemas sociales. La moral posconvencional parte de una apropiación crítica de las tradiciones entendidas como algo que proseguimos aproblemáticamente que otros han iniciado y hecho antes que nosotros-, sin caer en un fundamentalismo sobre nuestros propios valores adscriptos a una tradición en particular, para, en la distancia "hipotética" que otorga la posición "observador-participante" del discurso, confrontarlos con los principios abstractos -y supuestamente universales- de validez de una ética deóntico-discursiva.

Conforme al principio de universalización propuesto por Habermas una norma moral es válida cuando puede ganar el asentimiento de todos los afectados. Los partícipes del discurso moral se comprometen en una práctica comunicativa que reconoce la igualdad de 
El juicio por jurados populares: la experiencia en la provincia del Neuquén | 255

todos los partícipes y presupone la aceptación de ese principio a partir del cual sería posible la justificación racional de normas y principios morales.

En el caso del Jurado Popular, el veredicto es el resultado de esta práctica comunicativa que se despliega a partir de la ley común de la tierra, a través de la deliberación secreta de sus miembros, y constituye la decisión soberana en nombre de la comunidad afectada por el delito. Allí reside su legitimidad.

La idea de legitimidad se encuentra asociada a la motivación y ésta remite necesariamente a la ley. Legitimidad como adecuación a la ley, que no es mera concordancia formal de un procedimiento o medida con la ley positiva ${ }^{87}$ sino de aquellas con una ley que trasciende el marco positivo y al mismo tiempo es punto de referencia de este marco positivo, y razón de la justicia de ese ordenamiento jurídico. Aquello que nos permite valorar una norma positiva como justa. Legitimidad como adecuación a la ley justa. ${ }^{88}$

Este concepto de legitimidad impone el estudio de sus partes constitutivas: la Ley (y a fin de cuentas el Derecho mismo) y la Justicia en su relación con los principios morales de Autonomía, Dignidad e Inviolabilidad de la Persona (Nino), los Principios de Justicia rawlsianos (Iguales libertades [1] e Igualdad de oportunidades y Principio de Diferencia [2]), el concepto de derecho como conjunto de Reglas y Principios (dinámicos) de Dworkin -por oposición al derecho como conjunto de Reglas de Hart- y la Etica del discurso práctico de Habermas (para evaluar la validez de las normas a la luz de principios elaborados en base a un acuerdo racionalmente motivado).

En el contexto del proceso deliberativo de un jurado popular, la justicia de la ley se evidencia en la fusión de los puntos de vista de los participantes del discurso, situados por las costumbres, tradiciones y normas de equidad del lugar, con las reglas formales del derecho positivo aplicable al caso (introducido mediante las instrucciones) que fijan la "ley marco" de la deliberación.-

\footnotetext{
87 Remite sólo al presupuesto de validez de la norma: autoridad de la que emana y procedimiento de promulgación.

${ }^{88}$ De ahí la importancia de exponer los principios de justicia -como segmento de la moral-y la elaboración que de ellos realizan Rawls, Dworkin, Nino, Habermas, como así exponer la problemática de esta relación de la ley positiva con la Justicia que ha dado lugar dos corrientes antagónicas: iusnaturalismo y positivismo, abordadas en la tesis a través del pensamiento de Hart y Carrió, en alusión a Dworkin. En definitiva se trata de descifrar el concepto mismo del Derecho que excede con creces la mera interpretación de la norma escrita.
} 
La idea de motivación guarda una inmensa conexión con el paradigma mismo de la razón ${ }^{89}$. Algo está motivado (o fundado) cuando es racional. Y la razón puede ser meramente procedimental (formal) o hallarse comunicada a priori (Idea de Justicia ${ }^{90}$ ) o a posteriori (en la praxis de una convención ${ }^{91}$ ) con algún tipo de contenido necesario (material). En el caso del jurado popular, la razón procedimental se encuentra fijada por las instrucciones que el juez técnico a propuesta de las partes le trasmite al jurado.

Las instrucciones al jurado son el mecanismo procesal mediante el cual el jurado toma conocimiento del derecho aplicable al caso. El jurado es el juzgador de los hechos. Una vez adjudicados los hechos, el jurado debe entonces rendir su veredicto aplicando las normas de derecho sustantivo a los hechos, tal como han sido adjudicados por el jurado. Aún en la adjudicación de los hechos, el jurado debe recibir instrucciones sobre los principios correspondientes de derecho probatorio criminal, algunos de los cuales tienen rango constitucional, como la presunción de inocencia y el "quantum" de prueba (más allá de toda duda razonable). Por medio de las instrucciones al jurado, el juez le transmite al jurado en qué consiste su función, especialmente que tiene la obligación de juzgar al acusado solo a base de la prueba que se admita en el juicio (CHIESA, 1995, p.233).

Pero como veremos, la razón también se encuentra comunicada $a$ priori por la idea de Justicia o normas de equidad de la comunidad que integran los miembros del jurado que constituye la ley de la tierra. Idea de justicia que enlaza a posteriori con el contenido necesario de la convención que resulta de la deliberación de sus miembros en el caso concreto. Convención que, como luego se analizará, constituye la voluntad general del jurado popular, y que con ese alcance, afirma la legitimidad del veredicto frente a la sociedad.

Desde este enlace entre la norma positiva y su motivación racional (en una justicia formal o material), expresada en la ley justa, se arriba al tercer aspecto de la legitimidad de la norma jurídico penal, a saber, la eficacia (aceptación, acatamiento, obediencia, cumplimiento).

Así como un Estado es legítimo si existe un consenso entre los miembros de la comunidad política para aceptar la autoridad vigente, la ley positiva requiere la aceptación del sujeto/sociedad civil a quien se

\footnotetext{
${ }^{89}$ También llamado por los juristas "principio de razón suficiente".

${ }^{90}$ Rawls; Dworkin, Nino.

${ }^{91}$ En este sentido la Acción Comunicativa de Habermas.
} 
El juicio por jurados populares: la experiencia en la provincia del Neuquén | 257

dirige o regula, para que su actuación resulte genuinamente legítima. Existe una relación dialéctica entre la validez, justicia y eficacia de la ley de la que deviene su legitimidad que es especular en referencia a la relación dialéctica entre el sujeto, la sociedad civil y el Estado ${ }^{92}$. La sociedad civil es la que impone a través de sus representantes la validez de la norma (forma) y los principios de justicia que la rigen (razón suficiente) mientras que el sujeto que acepta la ley como válida y justa, en tanto miembro de la sociedad civil, le otorga eficacia, concediéndole al mismo tiempo su legitimidad. En la aceptación de la ley se funde la moralidad y la eticidad. La ley aparece para el sujeto como autolegislación..$^{33}$

La institución del jurado popular, previsto por la Constitución Nacional (arts. 24, 75 inc 12 y 118), confiere legitimidad a la decisión del jurado como ley del caso, desde que implica que los propios conciudadanos obligados por la ley positiva, aceptan la validez de la ley como un acto de autolegislación, en tanto miembros de la sociedad civil y fundadores de la norma que emerge del veredicto, receptando la legitimidad de la misma para casos análogos.

La participación de los ciudadanos en la aplicación de la ley penal a un caso concreto, actuando como jueces naturales en calidad de "vecinos" del lugar del hecho, legitiman la administración de justicia penal en la medida en que aceptan la validez de la ley positiva en el contexto en el que se actualiza el hecho que lesiona bienes fundamentales para la vida comunitaria. Ello teniendo como horizonte de interpretación, pautas de justicia y equidad situadas en un universo cultural, en un tiempo y espacio concreto.

El sujeto que mediante un acto voluntario transgrede el contrato social debe asumir las consecuencias de su acto. Consecuencias que vistas desde el planteo hegeliano, lo reconcilian con el Estado y sus conciudadanos, desde que la infracción representa la negación del contrato, y la sanción estatal, la negación de la negación, restaurando de este modo la paz social. Cuánto más acertado resulta este razonamiento cuando son los vecinos del acusado quienes lo juzgan, aplicando el derecho positivo desde una hermenéutica situada en el horizonte de la tradición, costumbres e ideas de justicia y equidad comunes al acusado, consintiendo de este modo, restaurar la paz social de la comunidad perturbada por el delito.

\footnotetext{
92 Adopto en este aspecto el planteo hegeliano de "Principios de la filosofia del derecho", Editorial Sudamericana, Buenos Aires, 2004.

${ }^{93}$ Obra de una moral formal (Kant) o de una voluntad general (Rousseau).
} 
La garantía del juez natural abarca tanto al tiempo como al lugar en donde reside el juez ciudadano. "Estamos acostumbrados a que, cuando pensamos en el juez natural pensamos en la predeterminación del juez como forma de evitar la manipulación política, que se acrecienta cuando el juez es designado ex post (...) el juicio por los pares, el juez natural, es también el juez con capacidad de comprender el caso de un modo distinto, con mayor capacidad de comprender el significado cultural del acto (...) la idea misma de ley escrita se va imponiendo frente a la antiquísima ley de la Tierra. Es decir, frente a la costumbre, vinculados a lo local, al terruño, al lugar de las comunidades a las que pertenecía el acusado. De ahí que fórum delicti comissi y juez natural están intimamente vinculados (...) es por ello que juez profesional -que es un invento de la inquisición en la Edad Media- está vinculado a la ley del Rey, al estatuto, al Código, a todo lo que está centralizado. El jurado popular, en cambio, es la mejor expresión histórica de la ley de la tierra, del lugar" (BINDER, 2013, p.34-35).

\section{El veredicto popular desde la opción republicana de Rousseau:}

Charles Edwyn Vaughan (1962, p.54/55) sostiene que el mérito de Rousseau radica en haber reencontrado la naturaleza racional y moral del hombre en la unión que él mantiene con el cuerpo político, oponiéndose al individualismo abstracto y al liberalismo de Locke. El sentido moral en cuanto deber para con los otros nace solo con la fundación del Estado; el sentido moral le concierne directamente a la comunidad así organizada y solamente de manera derivada a los individuos y la justicia solo puede ser garantizada a condición de haber reemplazado la voluntad del individuo por el conjunto de la comunidad.

Para Rousseau, el hombre civil solo es una unidad fraccionaria que depende del denominador, y cuyo valor está en su relación con el entero, que es el cuerpo social. La educación moral consiste en formar hombres vueltos hacia el bien general.

Por su parte, Cass R. Sunstein ${ }^{94}$ identifica cuatro rasgos como el núcleo de los temas fundamentales que definen el republicanismo como algo permanentemente actual: el republicanismo piensa la política como un proceso deliberativo, en el cual los individuos participan impulsados por su virtud cívica; su punto de partida es el horizonte de la igualdad política, convencido de la posibilidad de definir por medio del diálogo

${ }^{94}$ Beyond the Republian Revival, en The Yale Law Journal, XCVII, PAG. 1539-1589 
El juicio por jurados populares: la experiencia en la provincia del Neuquén | 259

una noción compartida del bien común, y atribuye el valor más alto a la idea de la ciudadanía activa. Deliberación, igualdad política, bien común y ciudadanía activa.

Idea de libertad que permite reunir a los hombres y no congregarlos, garantizar su libertad (moral y política) y no su independencia (individual). La persona pública se forma así por la unión de todas las otras y toma el nombre de república o cuerpo político. "La libertad consiste menos en hacer la propia voluntad que en no estar sometido a la de otro; consiste incluso en no someter la voluntad de otro a la nuestra" (ROUSSEAU, O.C., p.841).

La definición de la ley es la piedra angular de este sistema republicano de la libertad. Es poniendo a la ley por encima del hombre, haciendo del Estado una res publica, es decir, la cosa de todos, que puede gobernarse a los hombres sin hacerlos dependientes los unos de los otros. Solo hay libertad por la presencia de los otros y por la ley que sanciona el juicio de la legitimidad de todos sobre la conducta de cada uno: la ley introduce la libertad del todos y cada uno. La libertad como sujeción a la ley transforma al hombre en ciudadano. En lugar de conducirse por su propio juicio, el hombre conforma sus actos al juicio público de la ley:

[...] cuando el pueblo entero delibera sobre todo el pueblo, no respeta más que a sí mismo y si se forma entonces alguna relación, es la del objeto entero bajo un punto de vista con el objeto entero bajo otro punto de vista, sin que haya división de la totalidad. Entonces la materia sobre la que se estatuye es general como la voluntad que estatuye. Es este acto el que yo llamo una ley (ROUSSEAU, O.C., p. 379).

Un pueblo libre obedece, pero no sirve, tiene jefes y no amos; obedece a las leyes (ROUSSEAU, O.C., p.842). Para los republicanos, la cuestión de la libertad es mucho menos la de la posibilidad o no de mis acciones que la de su legitimidad o de su ilegitimidad, confundida, bajo el reinado de la ley, con la de su legalidad. El fundamento de la ley no es el simple consenso, sino su equidad, porque esta no es un puro formulario sobre el cual ponerse de acuerdo sino un valor con el cual comprometerse; por otra parte este valor debe ser discutido y reconocido. Para los republicanos, no se trata tanto de saber si otro puede o no interferir en mis acciones (cuál es el espacio de libertad y cuáles son sus 
límites) sino si tienen el derecho de hacerlo (cuál es la profundidad de ese espacio y las condiciones de su significado) (RUEFF, 2014, p. 141).

Esta definición de la libertad en la ley reconocida por todos abarca una filosofía de la deliberación (ROUSSEAUU, O.C., p.371), que articula una filosofía de libertad y una filosofía del habla pública ya que de-liberar es volverse libre al formular una decisión en el debate.

"Cuanto más importantes y graves son las deliberaciones, tanto más la decisión que prevalece debe acercarse a la unanimidad" (ROUSSEAU, O.C., p.441).

Lo que generaliza la voluntad es menos el número de votos que el interés común que los une: porque en esta institución cada cual se somete necesariamente a las condiciones que lo impone a los demás; admirable acuerdo de interés y de la justicia que da a las deliberaciones comunes un carácter de equidad que vemos desvanecerse en la discusión de todo asunto particular (...) ¿qué es, pues, con propiedad un acto de soberanía? Una convención del cuerpo con cada uno de sus miembros: convención legítima porque ella tiene por base el contrato social; equitativa porque es común a todos; útil porque no puede tener otro objeto que el bien general y sólida, porque tiene por garante la fuerza pública y al poder supremo (ROUSSEAU, O.C., p. 374).

Rousseau sostiene que ser hombre es ser libre, con todos, por todos, y para un sí autónomo que ya no está confinado en la subjetividad del yo. El paradigma de la libertad republicana que involucra una definición conjunta del individuo, del Estado y de la libertad. El individuo es un sujeto de derecho y de la libertad con capacidad para determinarse racionalmente; su humanidad es un programa que no puede mantener fuera de la comunidad de los hombres. Nuestra capacidad de ser agentes libres, es decir, hombres que eligen con conocimiento de causa entre dos alternativas y que son capaces de dar razones en apoyo de sus elecciones y de discutirlas permanece tributaria de un tipo de sociedad política. (ROUSSEAU, O.C. p. 936-937). Este individuo ya no es el homo oeconomicus de los liberales sino un ciudadano (ROUSSEAU, O.C., p. 360-362).

La ley instaura la comunidad de la libertad. Ser libre es hallarse asociado a los demás contra las interferencias de las cuales somos 
El juicio por jurados populares: la experiencia en la provincia del Neuquén | 261 protegidos por un sistema jurídico que prohíbe todo atentado a los derechos. La libertad debe ser común (implica la presencia de otros) e igual. (RUEFF, 2014, p.150). Es justamente la imputación de un delito a un conciudadano, como afectación de bienes sociales protegidos por la ley penal en nombre del pueblo (que representa el atentado a los derechos de los individuos que integran una comunidad dada), lo que habilita a los jurados populares a decidir la responsabilidad de ese conciudadano frente a la infracción a la ley que protege a la comunidad toda. La asignación de responsabilidad del transgresor al orden social es la que le permite cumplida la sanción consecuente- compensar su culpa y reintegrarse a la sociedad con sus pares, en igualdad de condiciones.

El modelo jurídico-liberal ha promovido la definición negativa de la libertad medida por la ausencia de toda intromisión de otro en mi esfera de acción. Con el revisionismo republicano, la libertad ya no se presenta como libertad negativa ni aún como libertad positiva, si la libertad negativa se define como una libertad de no-interferencia la libertad republicana es en adelante definida como no-dominación. La libertad republicana da cuenta no solo de las interferencias reales sino también de las interferencias potenciales: la libertad como anti-poder. La regulación legal del jurado popular recoge esta limitación potencial a la autonomía moral y política de los jurados, obligando a los mismos a denunciar todo tipo de presiones, influencias o inducciones externas que hubiesen recibido para emitir su voto en un sentido determinado. Se trata de garantizar que el veredicto popular quede librado de toda dominación que corrompa el proceso deliberativo.

El veredicto como acto de soberanía popular debe ser el resultado de una deliberación racional ajustada a la ley. En este sentido manifiesta el diptico del gobierno de la ley y de la soberanía popular y ordena una definición de la virtud cívica como afirmación del interés público sobre los intereses particulares. La virtud que la república exige de sus magistrados y de sus ciudadanos es exactamente la virtud cívica, idéntica en lo sustancial en los gobernantes y en los gobernados.

Por otra parte, el gobierno de la ley en el caso de los jurados, se instaura a través del juez profesional que dirige el juicio y explica el derecho aplicable al caso a los miembros del jurado mediante las instrucciones (en torno a las cuales gira la deliberación). La figura del juez encarna a la del "Legislador" de Rousseau: "la imagen rousseauniana de la gran política se identifica con el arte casi mágico del legislador que transforma una multitud en pueblo y funda instituciones capaces de perdurar a través de los siglos"(RUEFF, 2014, p.163). 
El veredicto del Jurado Popular instituye la ley del caso como ley situada en la coyuntura socio cultural de la comunidad perturbada por la acción criminal representada por las distintas subjetividades que integran el jurado. En esta ley concurren las conciencias de los participantes como manifestación del aspecto subjetivo de la ley. Cada conciencia abreva de la experiencia histórica cultural que constituye su identidad personal. Se trata de una conciencia fenoménica del ser, diametralmente opuesta a la conciencia kantiana, (nouménica del deber ser). Rousseau afirma que la conciencia es la voz que debe permitir una coincidencia universal sobre le bien. Es ella un principio de universalidad, una facultad universal para juzgar. "Hay, pues en el fondo de las almas, un principio innato de justicia y de virtud, sobre el cual, a pesar de nuestras propias máximas, juzgamos nuestras acciones y las de los demás como buenas o malas" (ROUSSEAU, O.C., p.598). Mientras que el sujeto de lo justo alcanza lo universal por la deliberación racional, el sujeto del bien llega a lo universal por el sentimiento que marca los límites mismos de la razón. Cuando la conciencia juzga, sus juicios son sentimientos (RUEFF, 2014, p. 163).

Puede afirmarse que la conciencia de los miembros del jurado, a partir de la prueba rendida en el juicio, se identifica con el sistema de valoración de la prueba denominado "intima convicción" prescripta por la ley de procedimientos para el caso del Jurado Popular. La confluencia entre la conciencia de cada uno de los miembros (como coincidencia universal sobre el bien) y la deliberación racional guiada por las instrucciones del caso es la que permite arribar al consenso necesario para adoptar un veredicto que se instituya en ley del caso, legitimando en este proceso la aplicación del castigo legal o su absolución.

El veredicto representa la resolución de la voluntad general que recoge las valoraciones singulares de cada miembro en función del entorno social y cultural y supera la mera suma aritmética de voluntades particulares de individuos abstractos - atomizados. Asimismo el veredicto supera la mirada universalista de la ley penal que sistematiza las afectaciones a los bienes sociales generales de una sociedad, en cuanto materializa una comprensión situada en la comunidad concreta donde se proyecta la infracción, desde los diversos actores que encarnan los intereses vitales de la comunidad (GASTIL, 2014, pp. 151-153).

\footnotetext{
${ }^{95}$ El jurado es una institución paradigmática de la sociedad politica, en donde los individuos actúan colectivamente por mandato del Estado para mediar entre las leyes y las acciones de la sociedad civil. Los jurados están involucrados en la gobernabilidad. En tal sentido los
} 
El juicio por jurados populares: la experiencia en la provincia del Neuquén | 263

El Jurado, como forma de asociación es siempre una forma singular, un individuo, pero el individuo mismo es un todo más o menos complejo de elementos compuestos bajo ciertas relaciones. La política es una composición de correlaciones de potencia en totalidades singulares transindividuales, imbricadas unas en otras. El universo sociopolítico es un universo relacional de esencias singulares constituidas en un proceso perpetuo de variaciones de las relaciones. Cada juicio exige una constitución distinta del jurado lo que aporta más dinamismo y espontaneidad a las asociaciones e impide cristalizar formas de dominación (tanto externas como internas a la asociación) y garantiza la igualdad recíproca de los miembros. Las buenas instituciones sociales son aquellas que mejor saben desnaturalizar al hombre, quitarle su existencia absoluta para darle una relativa y, transportar el yo en la unidad común (RUEFF, 2014, p.197).

\section{Conclusión:}

El jurado popular instaura un espacio público que se filtra en la administración del castigo, fragmentando el ejercicio del poder de las elites estatales tradicionalmente encarnadas en los jueces profesionales. En este proceso, se restituye protagonismo a los ciudadanos para resolver cuestiones de orden público que por su trascendencia los compromete al tiempo que fuerza a los individuos a asumir la responsabilidad de juzgar a sus pares desde sus propias perspectivas socio culturales singulares como reunidas bajo el imperio de la ley. Ésta se constituye en el universal aglutinante que fusiona la libertad moral con la libertad politica y en esta unión convierte a los individuos en ciudadanos de su comarca y los convoca como cuerpo político. La decisión instituye un universal situado en el horizonte de la comunidad en la que se produjo la afectación de bienes sociales primarios. Esta universalidad singular que representa la idea de espacio público es retomada por Arendt (1961, p. 220-221) quien propone reformular la universabilidad en términos de reversibilidad de

investigadores han reconocido largamente a los jurados como cuerpos politicos, demostrando cómo nuestros valores fundamentales moldean nuestros juicios. El sistema de jurados actúa de tal manera que convoca a ciudadanos particulares a la sociedad politica para ejercer el poder oficial del Estado, proveyendo una oportunidad excepcional de educar a los ciudadanos que lo integran en los roles y en las responsabilidades de la ciudadanía democrática. 
las perspectivas y búsqueda de comprensión del punto de vista de los otros $^{96}$.

Nuestra identidad se define en diálogo con las cosas que nuestros otros significantes desean ver en nosotros y a veces en lucha con ellas cobrando especial relevancia el reconocimiento del otro y nuestra condición potencial de iguales (dignidad), aquí una vez más emerge la problemática de la política de la Igualdad/Universalismo frente a la política de la Diferencia, lo que Charles Taylor (1993) cree resolver a través de una equilibrada reciprocidad (Rousseau) e igual respeto a las diferentes ideas de la vida buena (multiculturalismo o pluriculturalismo). La universalización de la presunción de valor de cada cultura resulta una extensión de la política de la dignidad (GADAMER, 1975) ${ }^{97}$.

Nos han venido entrenando para dominar a otros entes, y no para dialogar con ellos. Nos volvimos sordos (...) nos alejamos del signo diferencial de nuestra dignidad humana buscando reemplazarla por el éxito en una competencia en una posición central en el podio de la lucha por el dominio de todos los entes (...) sólo reemplazando el saber de dominus por el de frater podemos recuperar la dignidad humana (ZAFFARONI, 2012, p.126-134).

El jurado popular recoge la interculturalidad como mecanismos institucional y estructural a nivel político y social capaz de lograr la "unidad en la diversidad" en un ejercicio de democracia incluyente.

Se trata, entonces, de construir un universalismo pluritópico, situado, vivo, dinámico y móvil, anclado en el principio de cooperación comunitaria que deconstruya las falsas totalidades y construya una nueva forma de convivencia ciudadana en diversidad para alcanzar el buen vivir.

Como lo señala Seyla Benhabib (2006) es posible una defensa posilustrada del universalismo, sin apuntalamientos metafísicos ni

\footnotetext{
${ }^{96}$ A partir del "pensamiento ampliado" de Hannah Arendt: comunicación anticipada con otros con los que sé que tengo que llegar finalmente a algún tipo de acuerdo, poder de juzgar sobre un acuerdo potencial con otros en cuyo lugar debe situarse para pensar y cuya perspectiva debe tomar en consideración, sin los cuales nunca tiene la oportunidad de operar.

${ }^{97}$ Presunción de valor y no juicio de valor, que de por sí requiere una "fusión de horizontes" al decir de Gadamer mediante el desarrollo de nuevos vocabularios de comparación que permitirán la transformación de nuestras normas. En este mismo sentido, Foucault y Derrida afirman que todos los juicios de valor se basan en normas que en última instancia fueron impuestas por las estructuras de poder que, además, confirmaron.
} 
El juicio por jurados populares: la experiencia en la provincia del Neuquén | 265 presuntuosidad histórica. Un universalismo interactivo conocedor de las diferencias entre géneros, sensible al contexto y no indiferente a las situaciones, capaz de superar las ilusiones de una razón transparente y autojustificada, de un sujeto incorpóreo situado más allá de toda contingencia histórica-cultural. Es posible pasar de un concepto sustancialista de la racionalidad a otro de carácter discursivocomunicativo, que reconozca sujetos como criaturas finitas corporeizadas y frágiles que se construyen de modo narrativo ${ }^{98}$, como seres sociales capaces de habla, interacción y conocimiento, competentes para proyectar una narrativa al mundo de la que no sólo son autores sino actores, reformulando, el punto de vista moral como el logro contingente de una forma interactiva de racionalidad.

El desafío real del Jurado Popular reside en su potencia para desplegarse como espacio público donde habiten todos los espacios socio culturales los que, aunados como cuerpo político bajo el gobierno de la ley, ejerzan la responsabilidad de juzgar a sus pares, legitimando en ese proceso el sistema penal.

\section{BIBLIOGRAFÍA}

ARENDT, Hannah. The crisis in culture, in Between Past and Future: Six exercises in Political Thought. Meridian: Nueva York, 1961.

BUTLER, Judith. ¿Quién le canta al Estado Nación? Lenguaje política, pertenencia. Paidos: Buenos Aires, 2009.

BENHABID, Seyla. El Ser y el Otro en la Etica contemporánea. Gedisa Editorial, 2006.

BINDER, Alberto Conferencia en www.jucioporjurados.org, citado por Andrés Harfuch.

En: El juicio por Jurados en la Provincia de Buenos Aires, Buenos Aires, 2013.

CHIESA APONTE, Ernesto L. Derecho procesal penal de Puerto Rico y Estados Unidos. vol. II, Forum, San José de Puerto Rico, 1995.

${ }^{98}$ En este sentido Paul Ricoeur (1993) interpreta a la persona en la triple mediación de la acción, el lenguaje y la narración para dar fundamento a su constitución ética. 
DUSSEL, Enrique. Filosofia Etica Latinoamericana I, Presupuestos de una Filosofía de la Liberación. México: Edicol, 1977.

GADAMER, Hans-Georg. Verdad y Método. Fundamentos de una hermenéutica filosófica. Salamanca: Sígueme, 1975.

GARLAND, David. Castigo y Sociedad Moderna. Un estudio de teoría social. Siglo XXI, 1999.

GASTIL, John. Entre el Estado y la Sociedad. En: El juicio por Jurados. Investigaciones sobre la Deliberación, el Veredicto y la Democracia. 1ra Ed. Buenos Aires: Ad-Hoc, 2014.

GONZÁlEZ, Carlos Peña. Sobre la relación entre derecho y moral en una democracia (Revista de Derecho de la Universidad Austral de Chile, volumen 8 (citado el 25 de septiembre de 2015) suplemento especial, agosto 1997.

HANS, Valerie. Representación a través de la participación: un análisis multinivel de las deliberaciones del jurado. En: El Juicio por Jurados. Investigaciones sobre la deliberación, el Veredicto y la Democracia. 1 ra ed. Buenos

Aires: Ad-Hoc, 2014.

¿Cuál es la diferencia que hace un Jurado? En: El Juicio por Jurados Investigaciones sobre la Deliberación, el Veredicto y la Democracia. 1ra edición, Buenos Aires: Ad-Hoc, 2014.

HARFUCH, Andrés. El juicio por Jurados en la Provincia de Buenos Aires. Buenos Aires: 2013.

HEGEL. Principios de la filosofía del derecho. Editorial Sudamericana: Buenos Aires, 2004.

LEMPERT, Richard. A Jury for Japan? 40 Am. J. Comp. L., 37, 1992.

LEMPERT, Richard. Citicen Participation in Judicial decision Making: Juries, Lay Judges and Japan. St. Louis-Warsaw Transatlantic L.J., 1, 9-10, 2002. 
El juicio por jurados populares: la experiencia en la provincia del Neuquén | 267

LEVINAS, Emmanuel. Totalidad e Infinito. Ensayo sobre la exterioridad. Salamanca: Ed. Sígueme, 1977.

ROUSSEAU, Jean-Jacques. Cartas escritas desde la montaña, VIII, Obras Completas volumen III. Buenos Aires: Prometeo, 2008.

ROUSSEAU, Jean-Jacques. Contrato Social, II, VI, Obras Completas, volumen III. Buenos Aires: Prometeo, 2008.

RUEFF, Martin. Radical, Separado. La antropología de Jean-Jacques Rousseau y las teorias contemporáneas de la justicia. 1ra edición, traducción de Rodrigo Molina-Zabalía, Gonnet, Unipe: editorial universitaria, 2014.

SUNSTEIN, Cass R. Beyond the Republian Revival. En: The Yale Law Journal, XCVII.

TAYLOR, Charles. Multiculturalismo y la política del reconocimiento, FCE, 1993.

VAUGHAN, Charles Edwyn. Beyond the Republian Revival. En: The Yale Law Journal, XCVII.

. The political Writings of Jean-Jacques Rousseau. Oxford Basil Blackwell, 1962.

ZAFFARONI, Raul. La pachamama y el humano. Buenos Aires: Ediciones Colihue, 2012.

Recebido em: 26/08/2016

Aceito em: 20/09/2016 